\title{
EL RESARCIMIENTO EN CASO DE DESISTIMIENTO DEL CONTRATO DE OBRA, ¿ES REALMENTE DISTINTO DEL QUE DERIVARÍA DEL RÉGIMEN GENERAL?
}

\author{
IS THE COMPENSATION IN CASE OF WITHDRAWAL OF THE CONSTRUCTION \\ CONTRACT REALLY DIFFERENT FROM THE COMPENSATION UNDER THE \\ GENERAL SYSTEM?
}

Pablo Rodríguez -Palmero Seuma*

Fecha de recepción: 8 abril 2010.

Fecha de aprobación: 11 de mayo 2010.

\begin{abstract}
Resumen:
Generalmente se ha considerado que la facultad de desistir del contrato de obra contemplada en el artículo 1594 del Código Civil español es singular: no solo porque permite al promotor extinguir, por su sola voluntad, el contrato, sino también porque contempla una indemnización especial.

En este trabajo se pone en duda, principalmente, la segunda consideración: teniendo en cuenta que los tres conceptos contemplados en ese artículo normalmente coincidirán con la indemnización derivada de las reglas generales, la posible diferencia entre uno y otro régimen solo puede hallarse en el elemento subjetivo, esto es, en si el promotor ha actuado conscientemente de los daños que causa o no ha tenido otra alternativa que desistir. No obstante, tampoco esta diferencia con el régimen general es tan clara como pudiera pensarse.
\end{abstract}

Palabras clave: contrato de obra, desistimiento, indemnización.

Abstract:

It has been generally considered that the power to withdraw from the construction contract referred to in Article 1594 of the Spanish Civil Code is unique, not only because it enables the developer to terminate, voluntarily, the contract but also because it provides a special compensation.

This article mainly questions the second point: given that the three concepts mentioned in this article usually coincide with the compensation arising from the general rules, the possible difference between both systems can only be found in the subjective element, that is, if the developer has acted deliberately, being aware of the damages caused, or if he had no alternative but to withdraw. However, this difference to the general system is not as clear as one might think.

Key words : construction contract, withdrawal, compensation.

Responsable de Derecho Procesal,Manubens \& Asociados Abogados (Barcelona - España). prpalmero@ manubens.com

doi: 10.7770/RCHDYCP-V1N2-ART13 


\section{Características generales del artículo 1594 del Código Civil español}

El artículo 1594 del Código Civil español (en adelante "CC"), casi literal trasunto del 1794 del Código Civil francés ("Le maître peut résilier, par sa simple volonté, le marché a forfait, quoique l'ouvrage soit dejà comencé, en dédommageant l'entrepeneur de toutes ses déspenses, et tous ses travaux, et de tout ce qu'il aurait pu gagner dans cette entreprise") contempla la posibilidad del comitente, dueño o promotor de una obra de desistir unilateralmente de su ejecución, abonando al contratista determinada indemnización, que será posteriormente analizada. Dice el artículo: "El dueño puede desistir, por su sola voluntad, de la construcción de la obra aunque haya empezado, indemnizando al contratista de todos sus gastos, trabajo y utilidad que pudiera obtener de ella". En muy similares términos se pronuncia el artículo 1999 del Código Civil chileno: "Habrá lugar a reclamación de perjuicios, según las reglas generales de los contratos, siempre que por una o por otra parte no se haya ejecutado lo convenido, o se haya retardado su ejecución. Por consiguiente, el que encargó la obra, aun en el caso de haberse estipulado un precio único y total por ella, podrá hacerla cesar, reembolsando al artífice todos los costos, y dándole lo que valga el trabajo hecho y lo que hubiere podido ganar en la obra".

Generalmente, se ha afirmado que nos hallamos ante una singular manifestación de la denuncia o desistimiento unilateral del contrato, no contemplado como modo de extinción de las obligaciones en el artículo 1156 CC pero con otras singulares manifestaciones, concretamente en los contratos que presentan como factor común la confianza: sin carácter exhaustivo, los artículos 1583 CC (respecto del arrendamiento de servicios), $1700.4^{\circ} \mathrm{CC}$ (posibilidad de extinguir el contrato de sociedad por cualquier socio, siempre que lo inste de buena fe y en tiempo pertinente), 1733 CC (facultad del mandante de revocar el encargo), 1750 CC (posibilidad del comodante de pedir la restitución de la cosa, cuando no se haya pactado la duración del contrato), o 1775 CC (extinción del depósito a petición del depositante, aunque se haya pactado un plazo determinado).

Dejando constancia de la duda sobre si todos esos contratos se ven impregnados de tal dosis de confianza que justifique esa extinción unilateral. A continuación nos centramos en el transcrito artículo 1594 CC, comenzando por su fundamento, ejercicio y ámbito:

1. Respecto del fundamento, la mayoría de los autores españoles, pareciendo acudir a motivos de equidad -artículo 3.2 CC- y con base en la antigua doctrina francesa, considera que está constituido por la voluntad de evitar que el comitente pueda arruinarse durante la ejecución de la obra.

En esta línea, analizando el artículo 1535 del Proyecto del CC, ya expresaba GARCÍA GOYENA que el desistimiento "evita que el propietario cuya fortuna se halle comprometida repentinamente por sucesos imprevistos, se arruine comple- 
tamente con gastos en extremo dispendiosos. Puede también ocurrir que la obra no le sea ya útil ni necesaria" (1).

En la actualidad, la misma postura es seguida por autores como DE LA CÁMARA MINGO o RODRÍGUEZ MARÍN (2).

A mi juicio, tal posibilidad de ruina bien podría activar mecanismos menos traumáticos que el desistimiento: por ejemplo, un "ius variandi" similar al previsto, para las servidumbres, en el artículo 545 CC, o, caso de sucesos imprevisibles y de máxima gravedad, la cláusula "rebus sic stantibus". Sea como fuere, se hace necesario advertir que, al aplicar la facultad de denuncia, los Tribunales españoles prescinden por completo del fundamento descrito, pues le otorgan eficacia sin necesidad de que el dueño alegue (mucho menos, acredite) hallarse en una situación patrimonial comprometida.

Por otro lado, el fundamento consistente en que la obra haya devenido inútil o innecesaria para el promotor resulta, sencillamente, inaceptable: se trata de circunstancias cuyas repercusiones en modo alguno pueden lícitamente repercutirse al contratista.

Otros autores han manifestado que el desistimiento es una facultad inherente a la estructura del arrendamiento de obra: por ejemplo, en la doctrina italiana, ABELLO (3). Se trata de un aserto que desconozco si tiene algún contenido adicional a la simple constatación de que, en efecto, esa posibilidad se recoge en el articulado de aquel contrato.

De modo similar, se ha dicho que la denuncia es un privilegio concedido por la Ley al comitente: también en Italia, muy particularmente, MANGINI (4). Así esbozada, esta explicación ni siquiera merece el calificativo de fundamento: limitarse a afirmar que se trata de un privilegio, dado que nos hallamos ante una posibilidad solo excepcionalmente concedida, implica una mera constatación de Derecho positivo, en absoluto una exposición de la razón por la que tal facultad aparece recogida.

El último fundamento conocido del artículo 1594 CC es el ofrecido por SIRVENT GARCÍA, que afirma que, dado que el contrato de obra está principalmente previsto en interés del comitente, no tendría sentido que aquel se mantuviera cuando ese interés se ha desvanecido. Dice este autor: "La razón de ser de la norma contenida en este artículo pensamos que hay que ubicarla en la idea de que el contrato de obra es un instrumento que principalmente está al servicio de los intereses del comitente. Esto supone la necesidad de que el contrato exista sólo mientras el comitente siga teniendo interés en él. No tiene sentido que si el dueño, por la razón que sea, deja de tener interés en la obra se acabe de ejecutar ésta contra su voluntad" (5). 
Semejante concepción del contrato de obra, predicada además con carácter general, se halla perfectamente alejada de la realidad, que demuestra que, en la mayoría de las ocasiones, el contratista tiene en la obra (de cuya ejecución espera obtener importantes y legítimos beneficios) un interés incompatible con la libre posibilidad de que se vea súbitamente privado de ella.

No parece, pues, tarea fácil detectar el fundamento de la norma que estudiamos. Por mi parte, me permito avanzar que tal cúmulo de fracasos en ese bosquejo es síntoma de algo luego desarrollado: no nos hallamos ante una norma tan excepcional como a menudo se considera.

2. En relación con la declaración de voluntad mediante la que se ejercita el desistimiento, es pacíficamente considerada "ad nutum", unilateral -el constructor puede manifestar su rotunda oposición, sin que ello evite la extinción del contrato-, recepticia, irrevocable y no sometida a formalidad alguna.

Por todas, citamos como expresiva de tales caracteres la sentencia del Tribunal Supremo de 17 de junio de 2008 (RJ 2008/4700), que, con cita de otras, manifiesta: "(...) es una declaración de voluntad unilateral, recepticia e irrevocable que no está sometida a forma alguna, si bien conviene que sea notificada al contratista de forma fehaciente, pues ello facilitará la prueba del tiempo en que se produjo el desistimiento, y evitará discusiones sobre reembolsos de obras ejecutadas con posterioridad (aparte de otras, SSTS de 28 de julio de 2000, 31 de mayo de 2001 y 25 de noviembre de 2002)".

No obstante, esta sentencia acaba añadiendo algo que va más allá de lo declarado por otras resoluciones: "(...) la facultad de desistimiento no es ejercitada con corrección si simultáneamente no se ofrece indemnizar al contratista de la obra de todos los gastos, trabajo y utilidad que pudiera obtener de ella".

Al margen de la duda que introduce este pasaje en cuanto a los efectos de un desistimiento sin el contenido mencionado (¿qué significa que aquel no goza de "corrección"?), no parece que ese ofrecimiento pueda considerarse requisito de la denuncia. Obviamente, la liquidación de esas cantidades deberá tener lugar, pero exigir el ofrecimiento de su resarcimiento parece un formalismo excesivo. La mejor prueba de ello es que, como veremos, está admitido el desistimiento tácito.

3. Por lo que respecta al ámbito de aplicación del artículo 1594 CC, dos han sido las cuestiones habitualmente planteadas:

(i) En primer lugar, si únicamente opera en los contratos de obra concertados a precio cerrado (artículo 1593 CC) o tienen aplicación cualquiera que 
haya sido el sistema de fijación del precio. Si bien se trata de una cuestión expresamente resuelta, en el Derecho chileno, por el transcrito artículo 1999 de su Código Civil, en España ha dado lugar a ciertas dudas.

En un primer momento, quizá por influencia del Código Civil francés, cuyo artículo 1794 limita esta facultad a los arrendamientos con precio cerrado, la sentencia del Tribunal Supremo de 22 de junio 1911 (analizando un contrato para el arranque y calcinación de minerales) consideró que el desistimiento solo tenía cabida si el precio era alzado, basándose en el carácter restrictivo de la norma.

En el mismo sentido pareció posicionarse, si bien en un mero "obiter dictum", la sentencia del Alto Tribunal de 23 de noviembre de 1964 (RJ 1964/5453), al analizar un contrato para la impermeabilización de cubiertas.

Sin embargo, en la actualidad es pacífico que, al igual que se reconoce en el Derecho alemán (parágrafo 649 del BGB), el desistimiento puede jugar cualquiera que sea el sistema de fijación del precio y el objeto del contrato, pues el precepto no contiene discriminación sobre el tipo de contrato en los que debe encontrar aplicación ("ubi lex non distinguit, nec nos distinguere debemus"). Por todas, la sentencia del Tribunal Supremo de 25 de octubre de 1984 (RJ 1984/4976): "(...) es ya doctrina reiterada de esta Sala que el artículo 1594 es aplicable a toda clase de contratos de obra, no sólo a los realizados con ajuste a precio alzado-sentencias de 24 de enero y 19 de febrero de 1970 y 19 de noviembre de 1971-, puesto que el texto de esta norma no distingue según las clases de contratos a que haya de aplicarse".

En el mismo sentido, la doctrina: por ejemplo, DE LA CÁMARA MINGO o PUIG BRUTAU (6).

(ii) En segundo lugar, también se ha discutido si el artículo 1594 CC debe aplicarse con indiferencia de quién -comitente o contratista- suministre los materiales (1588 CC: "Puede contratarse la ejecución de una obra, conviniendo en que el que la ejecute ponga solamente su trabajo o su industria, o que también suministre el material").

Con alguna excepción -particularmente, TROPLONG (7)--, la doctrina considera también indiferente esta circunstancia: así se pronuncia, en la doctrina española y por todos, MANRESA (8).

4. Anticipando el tema principal de este artículo, deben dejarse consignadas las diferencias habitualmente predicadas (y más adelante puestas en entredicho) entre el precepto analizado y el general 1124 CC.

Los Tribunales españoles han reiterado hasta la saciedad que ambas normas son nítidamente diferentes, tanto en relación con el supuesto de hecho en ellas contemplados, como -lo que más interesa- respecto de los resarcimientos que otor- 
gan. Tal distinción, ya consagrada por las sentencias del Tribunal Supremo de 24 de enero de 1970 (RJ 1970/254) y 19 de noviembre de 1971 (RJ 1971/4906), ha sido especialmente destacada por sentencias como las de 4 de febrero de 1997 (RJ 1997/675) y 9 de marzo de 1999 (RJ 1999/1408): "El precepto citado [artículo 1594 CC] (...) responde a una situación distinta a la de la resolución del contrato conforme a lo pactado por aplicación del artículo 1124, de manera que no es posible asimilar ni confundir ambos artículos ni sus consecuencias jurídicas (...)".

En términos prácticamente idénticos, la sentencia del mismo Tribunal de 28 de julio de 2000 (RJ 2000/6202): "Decidido por el comitente de la obra el desistimiento de su realización en uso de la facultad que le confiere el art. 1594 del Código Civil (...) no cabe identificar con las consecuencias que, desde lo pactado y por resolución en caso de incumplimiento, establece el art. 1124, del propio Código (...) uno y otro precepto «responden a heterogéneos presupuestos, como también son disímiles sus consecuencias en orden a las respectivas indemnizaciones", reiterando lo que ya habian decidido las que la misma recoge y a las que cabe añadir las de 5 de mayo de 1983, 19 de noviembre de 1984, 7 de octubre de 1986 y, culminando sobre la autonomía entre los dos preceptos, la de 20 de febrero de 1993".

Insiste la sentencia del Tribunal Supremo de 26 de abril de 2005 (RJ 2005/3933): "Se trata de situación jurídica distinta a la de la resolución del contrato que autoriza el artículo 1124, carente de relación con el 1594, y no procede asimilar ni confundir el artículo 1124 con el 1594, como tampoco, lógicamente, sus consecuencias jurídicas".

Llevando al extremo esta doctrina, la sentencia del Alto Tribunal de 25 de noviembre de 2002 (RJ 2002/10275) Ilega a hablar de "incompatibilidad" entre las causas de extinción contractual previstas en los artículos 1594 y 1124 CC.

Actualmente, nuestro Tribunal Supremo sigue manteniendo la misma tesis, como refleja la sentencia de 19 de febrero de 2010: "(...) responden [los artículos 1594 y 1124 CC] a heterogéneos presupuestos, como también son disímiles sus consecuencias en orden a las respectivas indemnizaciones".

Dentro del estudio de la (anunciada) diferencia entre los artículos 1594 y 1124 CC, debemos citar algunas sentencias que, reiterando lo antes transcrito, añaden una expresión cuya posible relevancia será analizada al final de este artículo: me refiero a la manifestación de que el desistimiento puede lícitamente ejercitarse con independencia de los móviles o razones que el propietario pueda albergar.

Afirma, por ejemplo, la sentencia del Tribunal Supremo de 4 de febrero de 2002 (RJ 2002/1595): "(...) el derecho del contratista a percibir la indemnización a que 
se refiere el art. 1594 del Código Civil, no depende en absoluto de los móviles o razones que hayan inducido al propietario del terreno a desistir unilateralmente del contrato de obra concertado (...), libre arbitrio de su titular, sin necesidad de justificación de ninguna clase y depender la eficacia de la acción conferida por el segundo de la conducta observada por cada uno de los contratantes".

Casi literalmente, la sentencia del mismo Tribunal de 25 de noviembre de 2002 (RJ 2002/10275): "(...) el derecho del contratista a percibir la indemnización prevista en el art. 1594 del Código Civil no depende en absoluto de los móviles que hayan inducido al propietario a desistir unilateralmente del contrato de obra".

Por último, citamos la sentencia de 29 de septiembre de 2005 (RJ 2005/8892) "(...) el derecho del contratista a percibir la indemnización a que se refiere el art. 1594 del Código Civil, no depende en absoluto de los móviles o razones que hayan inducido al propietario del terreno a desistir del contrato de obra concertado (...), al libre arbitrio de su titular, sin necesidad de justificación de ninguna clase y depender la eficacia de la acción conferida por el segundo de la conducta observada por ninguno de los contratantes".

En concordancia con ello, los Tribunales tienen sentado que el ejercicio de la facultad otorgada por el artículo 1594 CC no requiere la concurrencia de los requisitos necesarios para la resolución contractual; en particular, del previo incumplimiento del contratista. Así lo reflejan, sin carácter exhaustivo, las sentencias del Tribunal Supremo de 13 de mayo de 1993 (RJ 1993/3546), 4 de febrero de 1997 (RJ 1997/ 675), 9 de marzo de 1999 (RJ 1999/1408), 18 de julio de 2000 (RJ 2000/6811), 31 de mayo de 2001 (RJ 2001/3449) y 25 de noviembre de 2002 (RJ 2002/10275).

\section{El supuesto de hecho que permite acudir al desistimiento unilateral}

Hemos visto cómo, salvo que se haya pactado otra cosa (la mayoría de la doctrina reconoce la posibilidad de limitar, con base en la autonomía de la voluntad, las causas que permiten su ejercicio), el desistimiento puede ser libremente ejercitado por el dueño de la obra. Se trata, en este sentido, de una declaración abstracta, pues no requiere expresión de la causa que lleva a actuar de ese modo; es más: ni siquiera exige concurrencia de causa alguna.

No obstante, no será extraño que el comitente que sopesa la conveniencia de paralizar la obra se plantee actuar de acuerdo con el artículo 1594 CC o, de modo aparentemente distinto, provocar la resolución contractual, para lo que le bastaría 
con incumplir sus más elementales obligaciones, forzando así al contratista a acudir al artículo 1124 CC.

Nótese que el planteamiento de esta alternativa únicamente tiene sentido si las consecuencias resarcitorias derivadas de cada opción (desistimiento o resolución) son distintas, algo que todavía no hemos analizado pero que, como hemos visto, consta reiteradamente declarado por los Tribunales españoles.

Pues bien, dejando para más adelante esta última cuestión, los Tribunales han venido asimilando al desistimiento ciertos comportamientos que, más que constituir una infracción contractual, reflejan una más profunda y global voluntad de no proseguir con la obra. Bien pudiera haber constituido obstáculo para este proceso el tan reiterado carácter excepcional del artículo 1594 CC; no obstante, como advierte CADARSO PALAU (9), nuestros Tribunales han ido dejando de prestar tanta atención a la naturaleza de la norma para centrarse en sus efectos. Buen ejemplo de ello es la sentencia del Tribunal Supremo de 15 de diciembre de 1981 (RJ 1981/5158), que manifestó que, con independencia del carácter otorgado al artículo 1594 CC, lo relevante es la determinación de sus efectos.

En cuanto a las conductas que, por su gravedad, han sido equiparadas al desistimiento, debe partirse de la manifestación general contenida en la sentencia del Alto Tribunal de 13 de mayo de 1993 (RJ 1993/3546), que, considerando que el desistimiento también puede ser tácito, afirmó que en esa categoría "cabría incluir la derivada de aquellas situaciones que demuestran, por su equivalencia, una evidente intención o voluntad de impago de la obra".

Ejemplo de conducta equiparada al desistimiento es la injustificada expulsión del contratista, contemplada en la sentencia del Tribunal Supremo de 20 febrero 1993 (RJ 1993/1003): “(...) probado por admitido, que los demandados expulsaron de la obra al actor, está fuera de duda que la reclamación actora, en el punto relativo al beneficio industrial, tiene acogida en el art. 1594 del Código Civil". En el mismo sentido, la sentencia de la Audiencia Provincial de La Rioja de 4 de enero de 2001 (JUR 2001/113645), en un caso en que, a pesar de que la promotora comunicó la resolución, lo hizo después de recibida provisionalmente la obra e impidiendo la entrada al contratista para ejecutar los repasos; puede leerse "(...) el impedir el acceso a la misma, equivale al desistimiento unilateral del dueño de aquella con anterioridad a su recepción definitiva, siendo a continuación cuando la actora resuelve el contrato mediante comunicación notarial, resolución posterior al desistimiento y aceptada de contrario, pero cuando ya la demandada había renunciado al cumplimiento íntegro del contrato". 


\section{El resarcimiento contemplado en el artículo 1594 CC}

Obviando el estudio de otras consecuencias del desistimiento unilateral (por ejemplo, la extinción del contrato o la necesidad de inmediata entrega de la obra por el contratista), nos centramos en el resarcimiento que este tiene derecho a percibir, consistente, según el precepto, en "todos sus gastos, trabajo y utilidad que pudiera obtener de ella [de la obra]".

Analicemos cada uno de esos conceptos, para posteriormente plantearnos si su resarcimiento tiene un alcance distinto al que derivaría del artículo 1124 CC.

\section{Gastos y trabajo}

Las cuestiones analizadas serán las siguientes: (a) si el resarcimiento de los gastos y trabajos debe ajustarse a los precios previstos en el contrato; (b) si, específicamente en los contratos por precio alzado, la indemnización debe ser proporcional a la obra ejecutada, sin alterar la referencia del precio total previsto, y (c) si esa indemnización únicamente comprende los gastos y trabajos ya incorporados a la obra.

(a) Respecto a si el resarcimiento debe ajustarse a los precios previstos en el contrato, la respuesta ha sido mayoritariamente negativa, de modo que los Tribunales vienen concediendo la indemnización que abarque el coste real y actual de los gastos y trabajos, prescindiendo del contrato y atendiendo a la correspondiente prueba pericial. Se percibe aquí, pues, una clara diferencia con lo previsto en el artículo 1595 CC, que, para el caso de fallecimiento del contratista, señala que la parte ejecutada se abonará "a proporción del precio convenido".

En el sentido apuntado, por ejemplo, se pronuncia la sentencia del Tribunal Supremo de 15 de diciembre de 1981 (RJ 1981/5158): "(...) sobrevenido el desistimiento de la parte demandada de la prosecución y finalización de la obra, tal circunstancia no puede imposibilitar ni mermar el derecho del actor a ser indemnizado de los gastos habidos hasta entonces, los cuales, a falta de acuerdo entre los litigantes, deben ser concretados por un experto conocedor de estas cuestiones, quien ha de valorar lo realmente hecho para poder así determinar el importe de lo indemnizable, y ello con independencia de lo inicialmente estipulado".

En idénticos términos, la sentencia del mismo Tribunal de 5 de mayo de 1983 (RJ 1983/2624): "(...) debiendo cuantificarse las cantidades e indemnizar a través de la oportuna prueba pericial, determinante de las obras realizadas y de su real importe, al margen del condicionado del contrato de ejecución de obra". 
Asimismo, citamos la sentencia del Tribunal Supremo de 8 de octubre de 1987 (RJ 1987/6766), que -analizando un caso de ejecución de obras de urbanización, en la que la contraprestación consistía en la mitad del precio resultante de la venta de ciertas parcelas- afirma: "(...) se aplica (en el quinto) con indudable acierto a investigar el montante de la indemnización acreditada "dejando al margen, como procede hacer, el condicionado del contrato (en especial, la cláusula relativa a la contraprestación dineraria por la ejecución de la obra contratada)». La indemnización la rige (sexto considerando) por "el importe total de las obras ejecutadas» (...) puntualizándose en torno a los conceptos de la indemnización debida al mismo que por "gastos» y "trabajos» han de entenderse los originados y realizados en la parte de la obra ejecutada, así jornales, honorarios y materiales invertidos".

Sin embargo, no falta alguna resolución en sentido contrario; muy particularmente, la sentencia del Tribunal Supremo de 7 de octubre de 1986 (RJ 1986/5330), que manifiesta debe atenderse a las previsiones de las partes: "(..) quiérese decir que por ese hecho ya venía constreñida a su abono, por preverlo el contrato en su cláusula cuarta, ya que de otra suerte se produciría un enriquecimiento injusto, con grave detrimento del equilibrio negocial, aparte de que los principios informantes de este singular contrato (...) exigen que el dueño de la obra satisfaga el precio de la ejecutada conforme a los módulos y previsiones convenidos".

(b) La indemnización, específicamente, en los contratos de obra por precio alzado. A pesar de alguna sentencia aislada (señaladamente, la del Tribunal Supremo de 22 de noviembre de 1974 -RJ 1974/4376-), los Tribunales mantienen aquí el mismo principio, de modo que el resarcimiento no tiene por qué coincidir con el resultado de proyectar, sobre el precio cerrado total, la parte de la obra efectivamente ejecutada.

Reflejo de esa regla es la sentencia del Tribunal Supremo de 15 de diciembre de 1981 (RJ 1981/5158) que, si bien afirma que en principio la valoración de los daños debe llevarse a cabo en proporción al precio total, considera que, de acreditarse que los costes son superiores al resultado de esa regla de tres, deben ser resarcidos. Dice la sentencia: "(...) si la ejecución fue bajo un precio alzado (...), si la parte proporcional del mismo correspondiente a la parte de obra ejecutada no cubriere los gastos realmente originados y el importe de los trabajos efectivamente incorporados, no podría utilizarse sin vulnerar el designio del art. 1594 del C. Civ., que, dicho sea una vez más, pasa por la más perfecta indemnidad del contratista, para efectuar el cálculo de la indemnización acreditada por éste y que, entendiéndolo de otro modo, dejaría de serlo partiéndose de aquel precio y fijando ésta a proporción de la obra ejecutada". 
En los mismos términos que la anterior resolución se pronuncia la sentencia del Tribunal Supremo de 8 de octubre de 1987 (RJ 1987/6766): "(...) aún existiendo precio alzado (...), prescindiéndose del precio si la parte proporcional correspondiente a la parte de obra ejecutada no cubriere los gastos realmente originados y el importe de los trabajos efectivamente incorporados, se efectúa según estos gastos e importes reales el cálculo de la indemnización por cuanto la facultad del artículo 1594 pasa por la más perfecta indemnidad del contratista (...)".

En la doctrina, algunos autores como SIRVENT GARCÍA se limitan a hacerse eco de las sentencias transcritas, afirmando pues que deberá estarse al precio pactado, salvo que el coste real sea superior (10). Igualmente, CARRASCO PERERA: "(...) la existencia de precio alzado no significa que sólo deba reembolsarse lo ejecutado en proporción a la cuantía fijada, pues la exigencia de indemnidad del contratista hay que salvarla siempre, por lo que, aun a costa de prescindir del precio alzado, el reembolso debe cubrir los gastos realmente originados y el importe de los trabajos efectivamente incorporados" (11).

Esta línea es criticada por CADARSO PALAU: de un lado, porque, procediendo de este modo, pudiera suceder que el contratista recibiera, como indemnización de la parte de la obra, más que lo que hubiera percibido de haberla terminado, contraviniéndose así la protección del dueño pretendida por la norma. De otro lado, porque la comparativa entre parte proporcional del precio y gasto real se contempla únicamente en una dirección (si el coste es superior al precio, debe indemnizarse el primero), sin plantearse la posibilidad contraria: que el coste sea inferior a la parte proporcional del precio (12).

Por nuestra parte, nos limitamos a dejar constancia que la solución aplicada por nuestros Tribunales no deja de ser consecuencia natural de la jurisprudencia, más amplia, de acuerdo con la que, a pesar de pactarse un precio cerrado, debe abonarse el coste de la mayor obra ejecutada (por todas, sentencias del Tribunal Supremo de 31 de octubre de 1998 -RJ 1998/8165-, 3 de noviembre de 1998 -RJ 1998/8735-, 13 de octubre de 1999 -RJ 1999/7424- y 20 de marzo de 2001 -RJ 2001/4742-).

Es más: esta más amplia doctrina, por muchos criticada -el contratista es un experto, que debe ser capaz de ajustar el precio al resultado que se le exige-, adquiere más sentido en caso de desistimiento del promotor, hecho que sí puede provocar el súbito desvanecimiento de los cálculos económicos del constructor.

(c) Respecto del tercero de los puntos anunciados -si la indemnización debe limitarse a los gastos y trabajos ya incorporados a la obra-, es postura pacífica que, lejos de ello, aquella abarcará también cualquier otro gasto en que haya incurrido el contratista en contemplación a la obra. 
Así lo manifiesta, por ejemplo, la sentencia de la Audiencia Provincial de Asturias de 10 de septiembre de 1998 (AC 1998/6532), que como consecuencia otorga el resarcimiento de los trabajos preparatorios para la obra, entre los que se incluía determinado estudio financiero acerca de la viabilidad de una solicitud de crédito.

El mismo criterio recoge la sentencia de la Audiencia Provincial de Salamanca de 20 de octubre de 2000 (JUR 2001/44432), para obligar a quien desistió a resarcir los gastos derivados de la elaboración de unos catálogos que habían sido ya aceptados por la propiedad.

Asimismo, la sentencia de la Audiencia Provincial de Murcia de 24 de febrero 2003 (JUR 2003/196681), recordando el mencionado principio general -"(...) el concepto global de gastos se comprenden todos los desembolsos que el contratista haya efectuado para el pago de bienes o servicios que, aunque no estuvieran incorporados a la obra, se hubieran hecho en atención a la misma"-, impone la indemnización de ciertas obras de fontanería, ya preparadas y cuya ejecución se frustró por el súbito desistimiento del dueño.

En similar sentido, las sentencias de la Audiencia Provincial de Barcelona de 13 de octubre de 2000 (JUR 2001/23047), y de la Audiencia Provincial de Madrid de 21 de junio de 2004 (JUR 2004/235563).

\section{El beneficio que el contratista pudiera obtener de la obra}

En esta sede, la cuestión más estudiada es si dicho beneficio debe ser cuantificado en el $15 \%$ generalmente considerado como beneficio industrial, materia sobre la que los Tribunales españoles oscilan (siempre a falta de pacto) entre la aplicación de ese porcentaje sin necesidad de prueba -así, por ejemplo, DEL ARCO TORRES y PONS GONZÁLEZ: (13)-, y la consideración de que aquel debe ser coherente con las circunstancias económicas del caso.

Buena muestra de la aplicación del mencionado porcentaje del $15 \%$ es la sentencia del Tribunal Supremo de 13 de mayo de 1993 (RJ 1993/3546), que afirma que aquel debe considerarse sin necesidad de actividad probatoria, por ser costumbre generalizada y notoria (artículo 1.3 CC, artículo 2 del Código de Comercio y 281.4 de la Ley de Enjuiciamiento Civil española). Dice esta sentencia: "(...) respecto a la base fáctica de la utilidad del $15 \%$ de la obra (...), su estimación es de uso generalizado al concurrir el supuesto al que se refiere el art. 1594 (...), sin que su existencia y exigencia, en razón a su específica índole y su fijación con arreglo al generalizado criterio estimativo del $15 \%$ del precio convenido, dependa de ninguna actividad probatoria practicada sobre la realidad de los daños y perjuicios sufridos por el contratista". 
De modo similar, la sentencia del mismo Tribunal de 15 de octubre de 1992 (RJ 1992/7821), que se pronuncia en los siguientes términos: "(...) en ausencia de pacto sobre beneficio industrial en la contraprestación de obras y servicios, los Tribunales han estimado en el tráfico negocial el quince por ciento del presupuesto convenido, que es algo superior al interés incrementado del dinero a efectos judiciales. Y es en el uso generalizado o la costumbre, en que se sigue manteniendo en muchos contratos de obra, en donde se cuantifica en el porcentaje correspondiente el beneficio industrial de la ejecución de la misma sobre los materiales aportados y las subcontratas convenidas".

Finalmente, la sentencia de 13 de mayo de 1983 (RJ 1983/2822) aplica el beneficio del $15 \%$, a pesar de que el tenor del contrato resultaba dudoso, pues diferenciaba un concepto de imprevistos del $1 \%$, otro de dirección del $5 \%$ y, finalmente, un estricto beneficio industrial de $9 \%$. La resolución, considerando que los tres conceptos deben quedar conceptualmente embebidos en el beneficio industrial, adiciona los porcentajes y fija aquel en el 15\%. Puede leerse: "(...) interpretado erróneamente el art. 1594, del C. Civ., al cifrar la indemnización que correspondía al contratista por aplicación del últimamente citado precepto en el 15 por 100 atribuible al Ilamado «beneficio industrial», siendo así que, según aduce, con la O. de 18 mayo 1960 en tres partidas correspondiente al 1 por 100 de imprevistos, al 5 por 100 de dirección de obra y al 9 por 100 de estricto beneficio industrial, entendiendo por ello que al no haberse realizado la obra contratada respecto a cuatro depósitos la única cantidad de procedente abono al contratista era la significada por el 9 por 100 del presupuesto de ejecución y no la del 15 por 100, acogiendo como criterio estimativo el generalizado que da como presupuesto una utilidad del 15 por 100 con carácter neto".

No obstante, como se ha anticipado, otras resoluciones afirman que la determinación del beneficio industrial en el $15 \%$ es meramente indicativa, y sujeta por tanto a su eventual coherencia con las circunstancias económicas y sociales. En esta línea, afirma la sentencia del Tribunal Supremo de 17 de octubre de 1996 (RJ 1996/7115): "El porcentaje del 15\%, que pretenden se aplique los recurrentes, no procede su acogida (...), no se ha establecido la utilidad del 15\% como un porcentaje fijo y no sometido a las circunstancias económico-sociales de los tiempos, al tratarse de un uso general (...), cambiante y acomodado a cada realidad histórico-social". De modo similar, la sentencia del Alto Tribunal de 28 de julio de 2000 (RJ 2000/6202) indica que, con prevalencia sobre dicho porcentaje, debe atenderse a la prueba efectivamente practicada: "(...) la sentencia recurrida, independientemente de abono de gastos y pago ya hecho de jornales, tiene presente, para llegar a fijar la indemnización por utilidad que estima adecuada para la contratista el precio de la obra y el porcentaje generalizado del $15 \%$ sobre el mismo, que no puede ser más que indicativo. En estas determinaciones, al igual que en la valoración de las pruebas, la facultad corresponde al juzgador de instancia como cuestión de hecho que es (...) y ha de prevalecer al no haberse acreditado que incide en error". 
Más reacia incluso a la aceptación de porcentaje alguno se muestra la sentencia del Tribunal Supremo de 25 de abril de 2003 (RJ 2003/3546), al señalar, no ya la preferencia de la prueba sobre costumbre alguna, sino la necesidad de estar siempre a dicha prueba, sin dar por supuesta la existencia de uso alguno: "(...) habrá de estarse a lo pactado, o al cálculo con arreglo a los márgenes o elementos que figuren en el contrato (Sentencia 30 mayo 1993 SIC), y, en su defecto, la determinación es una facultad que corresponde al juzgador de instancia como una cuestión de hecho (S. 28 julio 2000)".

\section{El resarcimiento vía artículo 1594 CC, ¿es distinto al que derivaría del 1124 CC?}

Analizados los conceptos resarcitorios contemplados en el artículo 1594 CC, surge inevitablemente la siguiente cuestión: ¿concede ese precepto una indemnización distinta a la que correspondería como consecuencia de una simple resolución contractual? ¿O concede una indemnización menor, bajo el entendimiento de que, dado que el dueño goza del privilegio de desistir, este quedaría diluido si no se le permitiera abonar un resarcimiento limitado? O, incluso, ¿prevé una indemnización superior a la que resultaría de las normas generales, precisamente para compensar la excepcionalidad de que una parte pueda libremente dejar sin efecto un contrato?

Pasamos a analizar esta cuestión:

a) La solución aparente: en cuanto pretende la indemnidad del contratista, el desistimiento acarrea la misma indemnización que resultaría de la aplicación de las reglas generales de responsabilidad contractual.

En efecto: muchas de las sentencias citadas al analizar los conceptos objeto de resarcimiento (gastos, trabajos y beneficio) afirman que la extensión de la indemnización debe ser aquella que logre la indemnidad del contratista, esto es: aquella que, apartando mentalmente el acaecimiento del desistimiento, consiga colocarle en la misma situación en que se hallaría si la obra hubiese finalizado correctamente.

En este sentido se pronuncia la ya invocada sentencia del Tribunal Supremo de 8 de octubre de 1987 (RJ 1987/6766), que, abandonando el estudio de la naturaleza del desistimiento unilateral, habla de "cierta unanimidad en la determinación de sus efectos, presidida por la idea de la indemnidad del contratista". En iguales términos, las sentencias del Tribunal Supremo de 10 de marzo de 1979 (RJ 1979/858) -que habla de "dejar indemne al contratista, es decir, a que el patrimonio de este no sufra menoscabo alguno como consecuencia de aquel desistimiento"-, 15 de diciembre de 1981 (RJ 1981/5158) -que impone el resarcimiento de "todas las utilidades que hubieran podido obtenerse en la obra en 
su totalidad, y no tan solo en la parte de la misma ya ejecutada"-, 7 de octubre de 1982 (RJ 1982/5543) y 19 de febrero de 2010.

No obstante, la sentencia más clara al respecto es la del Tribunal Supremo de 13 de mayo de 1993 (RJ 1993/3546), única de la que tengo conocimiento que afirma con nitidez que la resolución y el desistimiento desencadenan exactamente las mismas consecuencias resarcitorias, advirtiendo que, mediante la comprensión de las "utilidades", el artículo 1594 CC abarca también el resarcimiento del lucro cesante. Declara esta resolución: "si la calificación de la Sala de instancia acerca de la conducta del dueño de la obra (...) fuere, en lugar de una manifestación de desistimiento, la de un incumplimiento, se llegaría a la misma conclusión, dado que los daños y perjuicios probados serían solo el beneficio industrial, con lo que se desembocaría en igual resultado, toda vez que los hechos obligarían al Tribunal a dar respuesta por el cauce del art. 1124, máxime, cuando el resarcimiento de dicho precepto comprende tanto al "damnum emergens», como el "lucrus cesam», concepto este segundo que engloba la "utilidad» de que habla el 1594".

En términos similares, CARRASCO PERERA, que afirma que el desistimiento unilateral analizado "no constituye una facultad que exceptúe completamente [el significado del adverbio se nos escapa] el principio de vinculación contractual (arts. 1091, 1256 y 1258 CC), pues la "indemnización" debe cubrir totalmente el interés contractual positivo del contratista, de tal forma que, a pesar del desistimiento, este quede indemne" (14).

De hecho, la misma consideración fue realizada, mucho tiempo atrás, por el propio GARCÍA GOYENA, a la vista del anterior artículo 1535: "Ningún perjuicio se irroga por el artículo al arquitecto o empresario, pues se da todo lo que podría tener después de concluida la obra".

b) Esbozo de la diferencia entre ambos regímenes: el artículo 1594 CC prevé una indemnización que opera con abstracción del elemento intencional (culpa o dolo) a los efectos del artículo 1107 CC.

La cuidadosa lectura de las sentencias (muchas de las cuales, antes citadas) que enfatizan el conocido principio de que los motivos del desistimiento son irrelevantes, mueve a pensar -si bien ello no puede darse por cierto- que se está sugiriendo lo siguiente: el resarcimiento contemplado en el artículo 1594 CC no se verá agravado por un comportamiento tal que, de acuerdo con el régimen general de la responsabilidad civil, constituiría dolo, y obligaría a resarcir, no sólo los daños previsibles al contraer la obligación y necesaria consecuencia del incumplimiento, sino, yendo más allá, "todos los que conocidamente se deriven de la falta de cumplimiento de la obligación" (artículo 1107 CC). 
Para atisbar este entendimiento (cuya formulación expresa sería, en cualquier caso, de agradecer) resulta de ayuda la sentencia del Tribunal Supremo de 29 de septiembre de 2005 (RJ 2005/8892), que a la referida irrelevancia de los motivos añade que, en el marco del artículo 1594 CC, no cabe invocar circunstancias que tendrían relevancia en el ámbito del artículo 1124 CC. Dice esta resolución: "(...) el derecho del contratista a percibir la indemnización a que se refiere el art.1594 del Código Civil, no depende en absoluto de los móviles o razones que hayan inducido al propietario del terreno a desistir (...). Las consecuencias indemnizatorias (...), sin que para su cuantificación puedan tenerse en cuenta circunstancias relativas al cumplimiento o incumplimiento por los contratantes de sus obligaciones, susceptibles de ser invocadas al amparo del art. 1124 del Código Civil".

Ciertamente, a esta tesis podría objetarse que, entendido el dolo como conciencia de que se está incumpliendo una obligación, no requerido de específica voluntad de perjudicar o "animus nocendi" (analizando el mencionado artículo 1107 CC, dice la sentencia del Tribunal Supremo de 30 de noviembre de 1999 -RJ 1999/8439-: "El Código Civil no da una noción de dolo en el incumplimiento de la obligación (...), no siendo preciso para ello la voluntad de dañar o "animus nocendi», siendo bastante la voluntad consciente de incumplir") quien desiste siempre incurriría necesariamente en dolo, lo que privaría de sentido a la anterior explicación.

La respuesta que, a mi juicio, merece este obstáculo, se contiene en el apartado siguiente.

c) El alcance resarcitorio del artículo 1594 CC sí viene modulado por el reproche jurídico que merezca el comportamiento del comitente.

Lo expuesto impone adaptar el concepto de dolo al supuesto de hecho que estamos analizando, lo que considero puede hacerse como sigue: el desistimiento unilateral es simplemente culposo cuando concurren circunstancias que imponen ese proceder o, cuando menos, le otorgan razonabilidad (entorno económico, aparición de circunstancias sobrevenidas, etc.), y, además, se ejercita de acuerdo con las exigencias de la buena fe (artículo 7.1 CC): particularmente, informando con antelación al contratista de la posibilidad de desistimiento.

Por el contrario, el desistimiento es doloso si no se practica de acuerdo con tales parámetros: por ejemplo, cuando la causa reside en la comodidad o capricho del dueño, o en la localización de mejores alternativas económicas; también cuando, cualquiera que sea su origen, es comunicado súbitamente al contratista.

Me niego, pues, a entender que el artículo 1594 CC contemple con carácter general un resarcimiento más limitado que el derivado del régimen general de responsabilidad contractual -en primer lugar-, y que las motivaciones subjetivas 
que Ilevan al desistimiento sean perfectamente irrelevantes con vistas a determinar la indemnización que deberá soportar: tales elementos pueden ser estériles en relación con el efecto consistente en la extinción del contrato de obra qque sí tendrá lugar en cualquier caso, aun cuando el comportamiento del promotor merezca el máximo reproche), pero no a efectos del resarcimiento que deberá imponérsele.

Resultaría sencillamente inaceptable que un desistimiento caprichoso, e incluso ejercitado con la intención de causar daño al constructor, no conllevara mayor indemnización que el llevado a cabo por causas y mediante métodos distintos.

Nótese que los Tribunales ya han tenido en cuenta el ánimo del comitente en el marco del artículo 1594 CC: concretamente, para determinar si nos hallamos ante el supuesto de hecho en él contemplado. Como hemos comprobado, el ánimo del sujeto permite, en ocasiones, asimilar al desistimiento aparentes incumplimientos. Pues bien, del mismo modo ese ánimo debe contemplarse para fijar la indemnización a abonar por el promotor.

A este argumento, derivado de un adecuado entendimiento sistemático de la responsabilidad civil, puede aun añadirse otro: el artículo 1594 CC, al tratar de la indemnización derivada de la utilidad de la obra, contiene el pretérito del subjuntivo "pudiera", expresión sobradamente apta para, caso de que el desistimiento no se ejerza de acuerdo con la descrita buena fe, dar cabida a un resarcimiento de mayor proyección temporal, e incluso de daños meramente potenciales y cuya relación de causalidad se presente, hasta cierto punto, debilitada.

De este modo debe, por tanto, interpretarse el precepto: la tan reiterada irrelevancia de los motivos del propietario debe entenderse circunscrita a que su declaración de voluntad conllevará, en cualquier caso, la extinción del arrendamiento. Aquí topamos, efectivamente, con una especialidad respecto del régimen general de las obligaciones, en el que esa forma de actuar otorgaría al contratista, en primer término, el derecho a reclamar el cumplimiento "in natura" (artículo 1098 CC) y, por tanto, exigir la continuación de la obra.

Cosa bien distinta es la indemnización a cargo del comitente, modulable en atención a su comportamiento y que, a salvo la adaptación que exige el concepto de dolo, en nada diverge del régimen general.

\section{Bibliografía}

(1) Florencio García Goyena, "Concordancias, motivos y comentarios del Código Civil español", reimpresión de la edición de Madrid, 1852, realizada por LACRUz BERDejo, Zaragoza, 1974, página 803. 
(2) Fernando de la Cámara Mingo, "Derecho civil básico. Los contratos relacionados con la construcción", en "Tratado práctico del derecho referente a la construcción y a la arquitectura", tomo IV, Madrid, 1964, página 639.

Concepción Rodríguez Marín, "El desistimiento unilateral (como causa de extinción del contrato)", editorial Montecorvo, Madrid, 1991, páginas 333 y 334.

(3) Luigı Abello, "Tratatto della locazione", volumen IV, Nápoles-Turín, 1922, página 877.

(4) Vito ManginI, "Il contratto di appalto", en "Giurisprudenza sistematica civile e commerciale", Turín, 1972, página 290.

(5) Jorge Sirvent García, "El desistimiento unilateral del comitente en el contrato de obra", Revista de Derecho Patrimonial, n 8, Madrid, 2002, páginas 105 a 128.

(6) Fernando de la Cámara Mingo, op. cit., página 639. José Puig Brutau, "Fundamentos de Derecho Civil", tomo II, volumen 20, editorial Bosch, Barcelona, 1982, página 478.

(7) Raymond Théodore Troplong, "Droit civil expliqué", París, 1840, no 1030, páginas 244 y 245.

(8) José Manresa Navarra, "Comentarios al Código Civil español", tomo X, volumen II, Madrid, 1969, página 729.

(9) Juan Cadarso Palau, "El desistimiento del dueño en el contrato de obra y la indemnización al contratista", Poder Judicial, nº 10, 1987, página 97.

(10) Jorge Sirvent García, op. cit., página 120.

(11) Ángel Carrasco Perera, "Derecho de la Construcción y la Vivienda", editorial Dilex, Madrid, 1998, página 224.

(12) Juan Cadarso Palau, op. cit., páginas 98 a 100.

(13) Miguel Ángel del Arco Torres y Manuel Pons González, "Derecho de la Construcción. Aspectos administrativos, civiles y penales. Adaptado a la Ley de Ordenación de la Edificación", editorial Comares, Granada, 2003, página 436.

(14) Ángel Carrasco Perera op. cit., página 223. 